
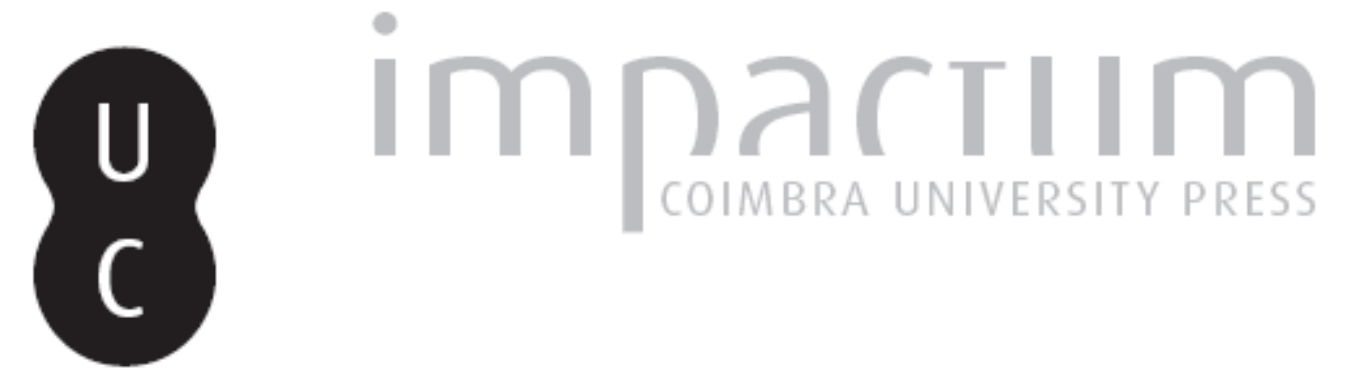

\title{
[Recensão a] Calderón de la Barca, Pedro (2016). La banda y la flor, ed. crítica Jéssica Castro Rivas
}

Autor(es): Núñez Sepúlveda, Ariel

Publicado por: Imprensa da Universidade de Coimbra

URL persistente:

URI:http://hdl.handle.net/10316.2/38659

DOI:

DOI:http://dx.doi.org/10.14195/1645-2259_15_15

Accessed : $\quad$ 26-Apr-2023 15:59:05

A navegação consulta e descarregamento dos títulos inseridos nas Bibliotecas Digitais UC Digitalis, UC Pombalina e UC Impactum, pressupõem a aceitação plena e sem reservas dos Termos e Condições de Uso destas Bibliotecas Digitais, disponíveis em https://digitalis.uc.pt/pt-pt/termos.

Conforme exposto nos referidos Termos e Condições de Uso, o descarregamento de títulos de acesso restrito requer uma licença válida de autorização devendo o utilizador aceder ao(s) documento(s) a partir de um endereço de IP da instituição detentora da supramencionada licença.

Ao utilizador é apenas permitido o descarregamento para uso pessoal, pelo que o emprego do(s) título(s) descarregado(s) para outro fim, designadamente comercial, carece de autorização do respetivo autor ou editor da obra.

Na medida em que todas as obras da UC Digitalis se encontram protegidas pelo Código do Direito de Autor e Direitos Conexos e demais legislação aplicável, toda a cópia, parcial ou total, deste documento, nos casos em que é legalmente admitida, deverá conter ou fazer-se acompanhar por este aviso.

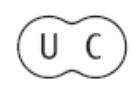




\section{Revista \\ de História \\ da Sociedade \\ e da \\ Cultura}

Século de Ouro

Siglo de Oro 
Calderón de la Barca, Pedro (2016). La banda y la flor, ed. crítica Jéssica Castro Rivas. Madrid/Frankfurt am Main: Iberoamericana/Vervuert, 326 pp., ISBN: 978-84-8489-9051

La publicación de la edición crítica de La banda y la flor, comedia palatina, se inscribe en el proyecto de edición de las Comedias completas de Calderón de la Barca emprendido por el Grupo de Investigación Siglo de Oro (GRISO) de la Universidad de Navarra, dirigido por el profesor Dr. Ignacio Arellano. Constituye este libro, pues, el número 14 de esta serie que, además, participa de la fundamental colección Biblioteca Áurea Hispánica de la Editorial Iberoamericana/ Vervuert. Sin duda, esta novedad editorial, a cargo de la Dra. Jéssica Castro, implica un importante y significativo avance en los estudios auriseculares por cuanto explora uno de los más interesantes territorios del universo cómico calderoniano: la comedia palatina, subgénero dramático con frecuencia dejado de lado en los acercamientos al rico y polimorfo corpus del gran dramaturgo barroco español. La edición en cuestión consta de un riguroso y acertado análisis literario de la comedia, junto con la anotación filológica, el estudio y fijación textual de la misma.

Tanto la autoría como la datación de la comedia no suponen mayor complejidad; la pieza fue escrita y representada en 1632, fecha que aparece históricamente vinculada al interior de la obra por medio de la inserción de una extenso romance en la primera jornada, que relata la ceremonia de la jura del Príncipe de Asturias Baltasar Carlos, hijo de Felipe IV. Castro Rivas realiza un minucioso estudio de este fragmento para establecer el interesante contexto histórico de producción de la comedia, observando el proceso estético de exaltación política de la monarquía de los Habsburgo, y cotejando el texto histórico calderoniano con otras obras que narran el mismo acto oficial, tales como diversas crónicas y-de manera más dilatada- el auto sacramental de Mira de Amescua, La jura del Príncipe. La relación de la jura dentro de La banda y la flor, entonces, le sirve a Castro en igual medida para, por un lado, determinar las insoslayables circunstancias históricas de la composición y montaje de la pieza teatral, y por otro lado, examinar su particular función en el interior de la ficción dramática.

Como adelanté antes, quizás el aspecto más relevante y sustancial del estudio literario de La banda y la flor que ofrece Castro Rivas sea el análisis de la obra a la luz de su inequívoca adscripción al subgénero de la comedia palatina. Así pues, la editora parte por la delimitación de los rasgos propios 
de este tipo de comedias, siguiendo, y a la vez ampliando, las productivas conceptualizaciones sobre el mismo asunto que han tratado Frida Weber de Kurlat, Miguel Zugasti, Joan Oleza, Eva Galar y Blanca Oteiza, entre otros. A partir del deslinde del sistema genérico áureo propuesto por Marc Vitse e Ignacio Arellano entre comedias serias y comedias cómicas -diferenciación fundada en la predominancia del efecto estético trágico o cómico-, Castro inscribe la palatina dentro del segundo campo, elaborando un detallado recorrido por su conformación histórico-dramática y examinado su evolución desde el teatro de Lope, pasando por Tirso, hasta su culminación en Calderón, teniendo siempre a la vista la dinámica y compleja relación entre práctica escénica y teorización en la preceptiva aurisecular - del Pinciano a Bances Candamo-. Asumiendo entonces dicho enfoque en el análisis del género, Castro Rivas traza la trayectoria evolutiva de la comedia palatina para señalar algunas de sus convenciones estructurantes en la obra de Calderón, las cuales pueden sintetizarse en la localización de la acción en coordenadas espacio-temporales alejadas de la familiaridad española-castellana (países exóticos e intemporales); personajes pertenecientes a la alta nobleza (condes, duques, príncipes, etc.) en concordancia con el espacio dramático eminentemente palaciego -de ahí la denominación-; la presencia de los vectores temáticos del amor, la amistad, el matrimonio, los celos, el secreto y el silencio; la «generalización del agente cómico» (aplicando lo que Arellano observaba en las comedias de capa y espada); la profusa utilización del mecanismo del enredo en la trama; el efecto de inverosimilitud; y, en suma, la dominante tonalidad cómica y lúdica de las piezas. Todo esto Castro lo pormenoriza y ejemplifica adecuadamente a lo largo del corpus completo del subgénero cómico palatino calderoniano.

De esta manera, queda de manifiesto al lector el marco genérico que determina la producción dramática, la recepción estética y el horizonte de expectativas de los espectadores coetáneos. La editora, así, entrega una imprescindible y útil perspectiva teórico-práctica de análisis para abordar las obras de este tipo, que sin duda servirá para las aproximaciones críticas futuras de los estudios calderonianos. Posteriormente, y con suma coherencia, Castro pondera La banda y la flor bajo el prisma que antes proyectó. La trama de la comedia se hilvana alrededor de los lances amorosos entre el galán Enrique y las hermanas Lísida y Clori, con la intervención del amigo del galán, Otavio, el Duque de Florencia y el padre de las damas, Fabio. El enredo se va intensificando por medio de la acumulación de equívocos típicos de las obras cómicas: ocultamientos, identidades veladas o fingidas, cartas, duelos que no se consuman, el matrimonio que ordena el caos de la intriga, etc. Perfecta- 
mente resumen la construcción lúdica del enredo amoroso y las disyuntivas risibles estos versos en boca de Enrique:

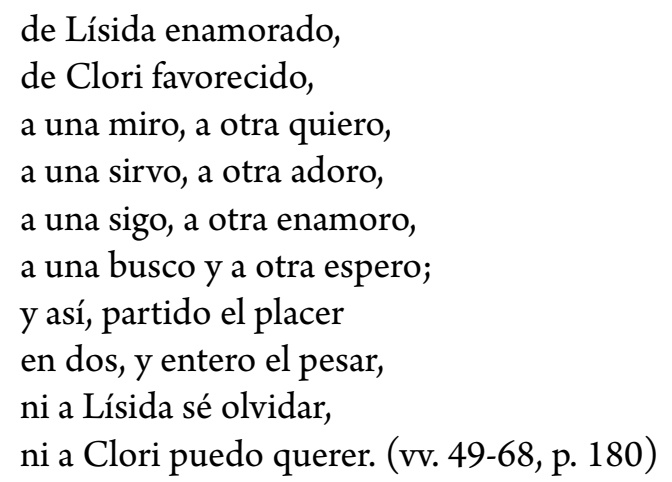

El galán, atrapado entre el favor de Clori y su amor hacia la hermana de la dama, Lísida, se verá luego enfrentado al «duelo de amor y amistad» (v. 669, p. 209) con su amigo Otavio; y para rematar la confusión cómica, aparecerá la intervención decisiva del Duque de Florencia, que introduce la lealtad como tercera fuerza movilizadora de la acción y la intriga. Dice Enrique sobre esta tríada central en el clímax del conflicto cómico:
¿Quién en el mundo pudo
$\tan$ fuerte lazo dar, tan fuerte nudo
de lealtad, de amistad y amor testigo,
de un señor, de una dama y un amigo? (vv. 1419-1422, p. 244)

Amor, amistad y lealtad hacia una dama, un amigo y un señor, en suma, configuran la entretenida trama de La banda y la flor. Otros elementos de la obra que Castro sopesa pertinentemente en su estudio literario son la localización de la historia -en la distanciada Florencia-, y los valores simbólicos de los colores azul y verde en relación, respectivamente, con la banda y la flor -objetos escénicos que dan título a la comedia- y su engarce con los celos y esperanzas de Clori y Lísida en un perfecto juego calderoniano de derivaciones y simetrías. Destaca, en este panorama, el énfasis que pone la editora en la relevancia que tienen los personajes femeninos en la consecución de la risa cómica o la presencia de la ingeniosidad risible apreciable, por ejemplo, en los estupendos versos del gracioso Ponleví: «^Ay, que me matan/ diez puñales de cristal/ con diez remates de nácar!» (vv. 1764b-1766, p. 260). Todo lo cual se inscribe coherentemente en la perspectiva genérica de la comedia palatina. 
La última dimensión que aborda el estudio literario que precede al texto de la comedia es la recepción de la obra. Castro indica la fortuna escénica de la pieza desde su inmediata representación hasta el siglo XX. En territorio español, nota la editora la escasa documentación sobre las puestas en escena realizadas durante el XVII, donde luego de su primer montaje en 1632, tuvo que esperar hacia el final del siglo para ser repuesta con mayor frecuencia en las tablas (1680, 1686, 1687 y 1692). El XVIII, a diferencia de lo se ha dicho, recibió con numerosos aplausos la obra calderoniana, al menos hasta antes del término del siglo cuando decae su popularidad. La banda y la flor en ese periodo se presentó tanto en los corrales madrileños del Príncipe y de la Cruz - con treinta y cuatro representaciones- como en otros teatros de las ciudades de Barcelona, Valencia, Sevilla y Valladolid. Con posterioridad, entrado ya el siglo XIX, la obra perderá vigencia en los recintos teatrales -se documentan solo ocho representaciones-, llegando al siglo XX que, a pesar de ver el rescate de la figura y dramaturgia de Calderón y su enaltecimiento en clásico, no registra ninguna puesta en escena de la comedia.

En el ámbito europeo, Castro Rivas señala una temprana traducción de la pieza palatina al francés en 1661, que acompaña el éxito del dramaturgo en esa lengua durante el XVII. Dos siglos después, La banda y la flor ingresará a la escena teatral alemana a través del movimiento romántico, que tan notablemente revitalizó la representación, lectura y valoración del arte de Calderón. La importante traducción de A.W. Schlegel -en el primer volumen de su Spanisches Theater en Berlín, 1803- sirvió para la difusión de la obra en tierras germanas. Otros hitos importantes de La banda y la flor en Alemania, nuevamente de mano del romanticismo, fueron la lectura que hizo Goethe de la obra y la ópera Liebe und Eifersucht (Amor y celos) compuesta en 1807 por E.T.A. Hoffmann -refundición de la versión de Schlegel-, que lamentablemente nunca vio su materialización en la escena. Castro también informa sobre la breve presencia del texto en Inglaterra y su viaje hacia tierras americanas, donde se tiene noticia de al menos tres presentaciones en Ciudad de México en los postreros años del siglo XVIII.

Pasando ahora al apartado del estudio textual, la editora reconstruye las vicisitudes de la transmisión de la obra, constituida principalmente por textos impresos: la mayoría corresponden a ediciones sueltas pertenecientes a los siglos XVII y XVIII, y otros son versiones contenidas en partes de comedias. Son diecisiete testimonios en total, dieciséis de ellos impresos, y uno es un manuscrito bastante tardío, de 1831. Según Castro, la edición princeps correspondería a la Parte Sexta de Comedias varias de diferentes autores impresa alrededor de 1654, la cual posee tres diferentes impresiones (PE1, PE2 y 
PE3). En 1668 se publica la Parte Treinta de Comedias nuevas y escogidas de los mejores ingenios de España, en donde aparece una versión de la comedia con el título alternativo Hacer del amor agravio. Vera Tassis publica en 1684 la Octava parte de comedias del célebre poeta español don Pedro Calderón de la $B a r c a$, en la que se incluye esta comedia palatina. Luego del examen detenido de la historia textual de la comedia, y tras efectuar el correspondiente análisis de las variantes, Castro Rivas decide tomar como texto base a PE1 por ser el que presenta mayor autoridad textual, aunque enmendando sus errores y lagunas con PE2 y Vera Tassis cuando estos ofrecían una lectura mejor. A esto añade un estema de la probable transmisión textual. La anotación del texto de La banda y la flor, siguiendo las normas editoriales del GRISO, comprende notas de tipo textual -que explican enmiendas hechas sobre el texto base, donde se indica y justifica su procedencia- y notas de tipo filológicas -que iluminan tópicos, motivos y alusiones literarias, generalmente con ejemplificaciones de otros usos en pasajes calderonianos u otros autores contemporáneos-. Es de resaltar que el aparato de notas que incluye la editora equilibra con pertinencia el esclarecimiento de diversos pasajes, su relación con el corpus calderoniano y el trabajo de fijación del texto.

En fin, esta valiosa edición crítica de la comedia palatina La banda y la flor de Calderón de la Barca supone una importante contribución al actual crecimiento del campo de estudio del universo cómico calderoniano, en sus variadas y polisémicas vertientes. La consistente propuesta interpretativa de la editora indica la vigencia y productividad de las lecturas cómicas de obras eminentemente cómicas -valga significativamente la redundancia-. Así, teniendo como sustrato del análisis las coordenadas y convenciones genéricas palatinas, Jéssica Castro Rivas ha logrado ampliar y enriquecer las aproximaciones al sistema teatral aurisecular. A su vez, el prolijo estudio y fijación textual aportan una edición filológica utilísima e ineludible que de seguro servirá para futuros trabajos sobre esta comedia y el género palatino. En síntesis, la fructífera labor calderoniana del Grupo de Investigación Siglo de Oro de la Universidad de Navarra tiene, en concordancia con su proyecto editorial, un sólido nuevo ejemplar disponible para los atentos lectores.

ARIEL NÚÑEZ SEPÚLVEDA 